\title{
The Hybrid New Keynesian Phillips Curve and Firm-Level Inflation Expectations in Japan
}

\author{
Kazuhiko Nakahira \\ Department of Business Administration and Information, Tokyo University of Science - Suwa, Nagano, Japan \\ Email address: \\ nakahira@rs.suwa.tus.ac.jp
}

\section{To cite this article:}

Kazuhiko Nakahira. The Hybrid New Keynesian Phillips Curve and Firm-Level Inflation Expectations in Japan. International Journal of Economic Behavior and Organization. Special Issue: Recent Developments of Economic Theory and Its Applications.

Vol. 3, No. 2-1, 2015, pp. 60-72. doi: 10.11648/j.ijebo.s.2015030201.20

\begin{abstract}
This paper examines inflation dynamics in Japan through estimations of the hybrid New Keynesian Phillips Curve. The estimation with the observed inflation rate in the corporate goods price index and that with the estimated firm-level expected inflation rate are considered. The firm-level expected inflation rate is estimated by the Kanoh (2006)-type extended Carlson-Parkin method. In addition, the validity of the pure forward-looking New Keynesian Phillips Curve and the implication of the flattening of the hybrid New Keynesian Phillips Curve are taken into account as the underlying points of interest. Consequently, our empirical study leads us to the following conclusions. First, the backward-looking factor has a dominant impact on inflation dynamics compared with the future element. Second, the forward-looking element has an unignorable effect on the inflation process, even though it is weaker than the backward-looking factor. Third, our result implies the incompleteness of the pure forward-looking New Keynesian Phillips Curve. It gives us the policy implication that the discussion of monetary policy should include a certain degree of emphasis on the backward-looking perspective in addition to the forward-looking perspective and must examine inflation persistence, although the forward guidance policy by the central banks is a recent important topic. Fourth, the degree of rationality of firm-level inflation expectations is not sufficient: firms' inflation expectations might not always be as exact as those made by the rational expectations hypothesis. Lastly, the slope of the hybrid New Keynesian Phillips Curve in Japan is very flat in recent years. It implies the Japanese central bank's current difficulty in conducting monetary policy in that inflation would be less responsive to movements in the measures of aggregate economic activities.
\end{abstract}

Keywords: New Keynesian Phillips Curve, Inflation Dynamics, Inflation Expectation, GMM

\section{Introduction}

Inflation dynamics is a prominent topic of macroeconomics. In other words, the evolution of inflation is a crucial issue, and a clear understanding of the inflationary process is necessary to proper planning of a monetary policy. The New Keynesian Phillips Curve (NKPC), which is constructed using microeconomic foundations from the New Keynesian DSGE (Dynamic Stochastic General Equilibrium) framework, is a useful tool in the study of modern issues of macroeconomics. From another perspective, the recent shift in emphasis from the traditional Phillips Curve to the New Keynesian Phillips Curve is because of the inability of the former to identify the developments of current inflationary processes in several countries. It is often reported that some countries with lively economic activity are accompanied by relatively low levels of inflation that cannot be explained by traditional economic theory. Furthermore, the New Keynesian Phillips Curve explicitly includes the forward-looking view, which is an important topic of recent discussions in the field of inflation dynamics and monetary policy.

The Literature on the New Keynesian Phillips Curve has continued to increase. For example, Galí and Gertler (1999), Galí, Gertler, López-Salido (2001), and Sbordone (2002) argue that the real marginal cost is a significant factor for analyzing inflation dynamics in the United States and in the Euro area. Galí, Gertler, and López-Salido (2005) describe the importance of the lagged inflation term in their models in considering the gradual response of inflation to monetary policy shocks. Zhang and Clovis (2010) conclude that further 
lags of inflation are necessary in the hybrid-type NKPC to rule out serial correlation. Rudd and Whelan (2005b) find that the New Keynesian pricing model cannot explain the importance of lagged inflation in a standard inflation regression, and that the forward-looking element plays a very limited role in describing the inflation process. Smets and Wouters (2003) and Giannoni and Woodford (2005) utilize partial dynamic inflation indexation. Woodfood (2003) studies the aggregate inflation by focusing on short-run nominal rigidity. Moreover, a number of recent studies deal with the flattening of the NKPC. For instance, Kuester, Müller, and Stölting (2009) consider the estimated pass-through of marginal costs and find that the NKPC looks flatter than its actual slope.

Managing "expectations" is an essential concern in modern monetary policy. Central banks try to measure the inflation expectation of the private sector, while the firms have a tendency to set their prices as a markup over a weighted average of the current and expected nominal marginal costs. Evans and Wachtel (1992), for example, conclude that inflation expectations in the United States are biased and inefficient predictors on the basis of their empirical study. Thomas (1999) finds the rationality of consumer expectations by using a measure of inflation expectations supplied by the University of Michigan Surveys of Consumers, but Carroll (2003) finds no rationality using the same measure. Brissimis and Magginas (2008) estimate NKPC with inflation forecasts given by the Federal Open Market Committee's Greenbook and the Survey of Professional Forecasters and conclude that expected inflation is the main determinant of current inflation. Gábriel (2010) reports the significant effects of changes in inflation expectations on prices and wages by structural vector autoregression analysis for three European countries. Oral (2013) uses some different quantification procedures for qualitative data, including the Carlson-Parkin method, the balance method, and the regression method, in order to estimate Turkish consumer inflation predictions, and rejects the "pure" backward- and forward-looking expectations hypotheses.

The discussion of monetary policy should include a certain degree of emphasis on the "backward-looking" perspective in addition to the "forward-looking" view, although the central banks' forward guidance policy, a recent significant issue, should be focused on. According to the forward-looking view, households and business sectors take advantage of information on the current and future movements of economic variables and policies. However, economic behavior is often adaptive or by rule of thumb, and it depends on past activity and inflations. Various empirical investigations, including some of the papers introduced above, have found evidence of backward-looking behavior. Moreover, the "flattening" of the NKPC must be considered because inflation would be less responsive to movements in the measures of aggregate economic activities such as the output gap if the slope of the NKPC is flat; this topic is related to the credibility implications of monetary policy. From these viewpoints, empirical estimation of the hybrid New Keynesian Phillips Curve, which enables us to investigate the effects of backward- and forward-looking factors on inflation dynamics and the flattening problem, is worthwhile.
Given the significances of the above issues, this paper examines inflation dynamics in Japan through estimations of the hybrid New Keynesian Phillips Curve (hybrid NKPC), which incorporates both backward- and forward-looking components. In particular, the estimation with the observed inflation rate in the corporate goods price index and that with the estimated firm-level expected inflation rate are considered. The firm-level expected inflation rate is estimated by the Kanoh (2006)-type extended Carlson-Parkin method. In addition, the validity of the pure forward-looking NKPC and the implication of its flattening are taken into account as the underlying points of interest. Furthermore, since we need to take a critical stance toward NKPC estimation using generalized method of moments (GMM) in terms of weak identification problem, the Hansen test for over-identification, the C-test for an instrumental variable's orthogonality, and the test utilizing the Cragg-Donald statistic and the Stock-Yogo critical values are implemented.

The reminder of this paper is organized as follows. Section 2 explains the basic formulation of the New Keynesian Phillips Curve. In Section 3, we estimate the inflation expectations using survey data and the Kanoh (2006)-type extended Carlson-Parkin method. In Section 4, we estimate the hybrid New Keynesian Phillips Curve using GMM to examine inflation dynamics in Japan. Section 5 presents concluding remarks.

\section{The Structure of New Keynesian Phillips Curve}

\subsection{The Basic Formulation of New Keynesian Phillips Curve}

The New Keynesian Phillips Curve (NKPC) describes the link between inflation and economic activities on the basis of firms' price-setting behaviors, marginal costs, and various economic activities. Concretely, it incorporates two significant factors: (i) the forward-looking character of inflation, which depends on a firm's price-setting decision and expectations of demands and costs in the future, and (ii) the linkages between inflation, real economic activity, and marginal cost.

The NKPC can be derived via the following procedure. ${ }^{1}$ The business sector is assumed to be a continuum of a monopolistic competitor indexed by $i \in[0,1]$, and it produces a differentiated good $\mathrm{Y}_{t(i)}$ with a nominal price $\mathrm{P}_{t(i)}$. Firm $i$ faces an isoelastic demand curve given by $\mathrm{Y}_{t(i)}=\left(\frac{\mathrm{p}_{t(i)}}{\mathrm{P}_{t}}\right)^{-\varepsilon} \mathrm{Y}_{t}$. The production function for firm $i$ is given by a special type of Cobb-Douglas technology: $\mathrm{Y}_{t(i)}=\mathrm{A}_{t} \overline{\mathrm{K}}_{t(i)}^{\alpha} \mathrm{N}_{t(i)}^{1-\alpha}$, where $\mathrm{A}_{t}$ is a technological factor, $\overline{\mathrm{K}}_{t(i)}$ is the fixed firm-specific capital stock, and $\mathrm{N}_{t(i)}$ is the employment.

Households are assumed to be paid the nominal wage $\mathrm{W}_{t}$, and each firm faces the same nominal cost of production. The Dixit-Stiglitz-type aggregate price $\mathrm{P}_{t}$ and output $\mathrm{Y}_{t}$ are represented by

\footnotetext{
${ }^{1}$ See Goodfriend and King (1997), Galí, Gertler, and López-Salido (2001), and Scheufele (2010) for explicit derivations.
} 


$$
\begin{gathered}
\mathrm{P}_{t}=\left[\int_{0}^{1} \mathrm{P}_{t(i)}^{1-\varepsilon} d i\right]^{\frac{1}{1-\varepsilon}}, \\
\mathrm{Y}_{t}=\left[\int_{0}^{1} Y_{t(i)}^{\frac{\varepsilon-1}{\varepsilon}} d i\right]^{\frac{\varepsilon}{\varepsilon-1}},
\end{gathered}
$$

where $\varepsilon$ is the constant price elasticity of demand. Because investment and foreign trade are abstracted, output $\mathrm{Y}_{t}$ equals consumption $\mathrm{C}_{t}$.

Without any price frictions, firms would set the price level $\mathrm{P}_{t(i)}^{*}$ to maximize the real profit at any given time. The optimization framework gives the markup equation $\mathrm{P}_{t}^{*}=\rho+$ $\mathrm{mc}_{t}$, where $\rho=\log \left(\frac{\varepsilon}{\varepsilon-1}\right)$ represents the fixed markup and mc is the log nominal marginal cost. In this framework, firms set nominal prices in the Calvo (1983)-type staggered fashion facing constraints on the frequency of price adjustment. With this specification, the probability that a firm resets the price in any period $t$ is $1-\theta$, where $\theta$ is the measure of the degree of price rigidity or the fraction of firms that keeps prices constant. Since this probability is time-independent, the duration (or mean lag) of price adjustment becomes $\frac{1}{1-\theta}$. Therefore, a fraction $1-\theta$ of producers reset their prices, while the others $\theta$ remain unchanged. By applying the property of the law of large numbers and the log linearization of the price index around the steady state of zero inflation, we obtain the following expression for the evolution of the $\log$ price $\mathrm{P}_{t}$ as a convex combination of the log of the lagged price level $\mathrm{P}_{t-1}$ and the $\log$ of the newly optimized price $\mathrm{P}_{t}^{*}$ :

$$
\mathrm{P}_{t}=(1-\theta) \mathrm{P}_{t}^{*}+\theta \mathrm{P}_{t-1}
$$

All the firms that reset their prices in period $t$ choose the same value of $\mathrm{P}_{t}^{*}$ since there are no firm-specific state variables. In addition, with the given technology, factor prices, constraint on price adjustment, and reset probability $1-\theta$, a firm that resets its price in period $t$ tries to maximize its expected discounted profits. Considering these elements, the Calvo-type optimized reset price can be given as ${ }^{2}$

$$
\mathrm{P}_{t}^{*}=(1-\beta \theta) \sum_{k=0}^{\infty}(\beta \theta)^{k} E_{t}\left[\mathrm{mc}_{t, t+k}^{\mathrm{n}}\right]
$$

where $\beta$ is a subjective discount factor and $\mathrm{mc}_{t, t+k}^{\mathrm{n}}$ is the logarithm of the nominal marginal cost at time $t+k$ with respect to a firm that last changed its price at time $t$. This specification implies that firms that reset prices in period $t$ will take into consideration the expected future stream of the nominal marginal cost expressed in percent deviation from the steady state with the chance that the newly reset price might be subject to adjustment constraints in the future. Therefore, prices are expected to remain unchanged for an extended period, and firms place more weight on expected marginal costs when they set current prices as $\theta$ increases.

The next problem is to find a plausible expression of the marginal cost in equation (4) as an observable measure. If we assume a simple Cobb-Douglas production function, we have

\footnotetext{
${ }^{2}$ The fixed markup $(\rho)$ disappears because all variables are expressed in deviation from the steady state.
}

$$
\mathrm{Y}_{t}=\mathrm{A}_{t} \mathrm{~K}_{t}^{\alpha} \mathrm{N}_{t}^{1-\alpha}
$$

where $\mathrm{Y}_{t}$ is production, $\mathrm{A}_{t}$ refers to technology, $\mathrm{K}_{t}$ denotes capital, and $\mathrm{N}_{t}$ is labor. Cost minimization with this technology implies that the real marginal cost equals the real wage divided by the marginal product of labor. Therefore, the real $\mathrm{MC}$ at time $t+k$ for a firm that optimally sets its price at time $t$ is given by

$$
\mathrm{MC}_{t, t+k}=\frac{\frac{\mathrm{w}_{t+k}}{\mathrm{P}_{t+k}}}{(1-\alpha) \frac{\mathrm{Y}_{t, t+k}}{\mathrm{~N}_{t, t+k}}},
$$

where $\mathrm{Y}_{t, t+k}$ represents output, $\mathrm{N}_{t, t+k}$ indicates employment, and $\alpha$ is the curvature of the production function for a firm that sets its price in period $t$ at the optimal value $\mathrm{P}_{t}^{*}$. Because the real $\mathrm{MC}$ of an individual firm is unobservable, it is helpful to define the average marginal cost depending only on aggregates:

$$
\mathrm{MC}_{t}=\frac{\frac{\mathrm{W}_{t}}{\mathrm{P}_{t}}}{(1-\alpha) \frac{\mathrm{Y}_{t}}{\mathrm{~N}_{t}}}=\frac{\mathrm{S}_{t}^{\mathrm{n}}}{1-\alpha},
$$

where $S_{t}^{\mathrm{n}} \equiv \frac{\mathrm{w}_{t} \mathrm{~N}_{t}}{\mathrm{P}_{t} \mathrm{Y}_{t}}$ is the labor share. ${ }^{3}$ Letting the lower-case italic letters $m c$ and $s$ describe the deviations from each steady-state in the logarithm, it becomes

$$
\widehat{m c} t=\hat{s}_{t}
$$

Making the assumption of Cobb-Douglas technology with an isoelastic demand curve following Woodford (1996), Galí, Gertler, and López-Salido (2001), and Sbordone (2002), we have the log-linear connection between $\mathrm{MC}_{t, t+k}$ and $\mathrm{MC}_{t}$ :

$$
\widehat{m c}_{t, t+k}=\widehat{m c}_{t+k}-\frac{\varepsilon \alpha}{1-\alpha}\left(\mathrm{P}_{t}^{*}-\mathrm{P}_{t+k}\right),
$$

where $\widehat{m c}_{t, t+k}$ and $\widehat{m c}_{t+k}$ are the deviations in the logarithms of $\mathrm{MC}_{t, t+k}$ and $\mathrm{MC}_{t+k}$, respectively, from their steady-state values. ${ }^{4}$ Combining equations (3), (4), and (9) gives the basic formulation of the (marginal-cost-based) NKPC: ${ }^{5}$

$$
\pi_{t}=\beta E_{t}\left[\pi_{t+1}\right]+\lambda \widehat{m c}_{t}
$$

where

$$
\lambda \equiv \frac{(1-\theta)(1-\beta \theta)(1-\alpha)}{\theta[1+\alpha(\varepsilon-1)]} .
$$

Since the slope coefficient $\lambda$ is decreasing in $\theta$ (the frequency of price adjustments or the fraction of firms that keeps prices constant), a smaller fraction of firms resetting the prices of their productions implies that inflation will be less sensitive to the changes in the marginal cost. $\lambda$ is also decreasing in $\alpha$ (the elasticity of substitution between factor

\footnotetext{
${ }^{3}$ Equation (7) is derived as $\mathrm{MC}_{t}=\frac{\mathrm{W}_{t}}{\mathrm{P}_{t}} \frac{1}{\partial \mathrm{Y}_{t}}$.

${ }^{4}$ In the case of linear technology or cofistant returns to labor $(\alpha=0)$, all firms are confronted with the same marginal cost.

${ }^{5}$ Real marginal cost can be expressed as a related variable of the output gap. Following this condition, the output-gap-based NKPC is derived. For the concrete discussions, see Walsh (2010), Galí (2008), and Woodford (2003).
} 
inputs or the curvature of the production function) and $\varepsilon$ (the elasticity of demand). Thus, the larger $\alpha$ and $\varepsilon$ cause more sensitive marginal cost of an individual firm to deviations of its price from the average price level.

\subsection{The Hybrid Model of the New Keynesian Phillips Curve}

The basic New Keynesian Phillips Curve expressed in equations (10) and (11) postulates a relatively low persistence of inflation. However, it is not always consistent with the actual inflation dynamics and not always data coherent because of price rigidities. An alternative formulation of the NKPC proposed by Galí and Gertler (1999) and Galí, Gertler, and López-Salido (2001) that considers this fact incorporates the backward-looking component or lagged dependence of inflation as well as the forward-looking element. The derivation of this "hybrid model" starts by modifying the Calvo-type contract with the introduction of two kinds of firms. A subsample of firms $1-\omega$ has forward-looking price-setting behavior, while the remaining fraction $\omega$ sets their prices with a backward-looking rule of thumb. Therefore, the aggregate price level is given by the equation

$$
\mathrm{P}_{t}=\theta \mathrm{P}_{t-1}+(1-\theta) \overline{\mathrm{P}}_{t}^{*},
$$

where $\overline{\mathrm{P}}_{t}^{*}$ represents the index of prices at time $t$ such that

$$
\overline{\mathrm{P}}_{t}^{*}=\omega \mathrm{P}_{t}^{b}+(1-\omega) \mathrm{P}_{t}^{f},
$$

where $\mathrm{P}_{t}^{b}$ is the price for the backward-looking rule of thumb and $\mathrm{P}_{t}^{f}$ is the price for forward-looking firms that behave just as basic Calvo-type sectors. Thus, the behavior of forward-looking firms can be described as

$$
\mathrm{P}_{t}^{f}=(1-\beta \theta) \sum_{k=0}^{\infty}(\beta \theta)^{k} E_{t}\left[\mathrm{mc}_{t+k}\right]
$$

Galí and Gertler (1999) assume that backward-looking firms follow rule-of-thumb behavior based on recent aggregate pricing. In this sense, $\mathrm{P}_{t}^{b}$ can be expressed as

$$
\mathrm{P}_{t}^{b}=\overline{\mathrm{P}}_{t-1}^{*}+\pi_{t-1} \text {. }
$$

Since forward-looking firms set prices as markups over their marginal costs and fix prices supposedly for more than one period, their decisions on prices are based on the expected future streams of marginal costs. On the other hand, backward-looking firms fix prices on the basis of the equilibrium levels in the previous period.

A combination of equations (10) through (15) can be used to derive the reduced-form specification of the (marginal-costbased) hybrid New Keynesian Phillips Curve: ${ }^{6}$

$$
\pi_{t}=\gamma_{b} \pi_{t-1}+\gamma_{f} E_{t}\left[\pi_{t+1}\right]+\lambda \widehat{m c}_{t},
$$

where

$$
\begin{aligned}
& \gamma_{b}=\omega \emptyset^{-1}, \\
& \gamma_{f}=\beta \theta \emptyset^{-1}
\end{aligned}
$$

\footnotetext{
${ }^{6}$ This kind of specification is regarded as a "hybrid-type" NKPC in the sense that it incorporates both forward- and backward-looking components.
}

$$
\begin{aligned}
& \emptyset=\theta+\omega[1-\theta(1-\beta)], \\
& \lambda \equiv \frac{(1-\omega)(1-\theta)(1-\beta \theta)(1-\alpha)}{\emptyset[1+\alpha(\varepsilon-1)]} .
\end{aligned}
$$

This hybrid specification can be regarded as a special case of the basic formulation of NKPC described by equations (10) and (11) with a backward-looking element, $\omega$.

\section{Estimation of Inflation Expectations}

\subsection{Survey Data and Inflation Expectations}

Inflation expectations can be estimated using the data obtained from the social survey without any particular economic models. Usually, we find two patterns of survey data on inflation expectations, "qualitative" and "quantitative". In "qualitative" surveys, respondents answer in a qualitative manner to such questions as, "Do you think that the price level (or inflation) will have gone up (or down) one year (or quarter) from now?" The data on forecasted price levels (or inflation) given by this sort of survey are presented in a qualitative statistic form that indicates whether the majority of the polled respondents anticipate that inflation will rise, remain constant, or decline in the future. Thus, this type of survey describes the general tendency of expectations. On the other hand, respondents give quantitative answers in "quantitative" surveys. In this respect, it seems desirable to estimate inflation expectations via a "quantitative" survey. However, the result of "quantitative" surveys may be distorted by measurement or sampling errors. Hence, it is preferable to utilize a "qualitative" survey with a special method of quantifying qualitative data.

\subsection{The Kanoh (2006)-type Extended Carlson-Parkin Method}

As discussed in the previous section, a method of quantifying qualitative survey data is required. However, we should pay close attention to some problems. For instance, respondents only indicate whether they think prices (or inflation) will "rise," "fall," or "remain unchanged" for certain periods ahead in the survey, and a mean value cannot be obtained since the answers are given in a qualitative manner. To deal with this sort of problems, various techniques, such as the Carlson-Parkin method, the balance method, the regression method, and others have been developed.

The Carlson-Parkin (1975) method $^{7}$ is a typical probability approach to estimating expected inflation. It assumes that respondents' qualitative responses follow an individual probability distribution that is statistically independent and normally distributed with finite mean and variance, and that the respondents report the mean of the distribution. In addition, it postulates that respondents form an inflation expectation at time $t$ for the time $t+1$ when they respond to the survey. The joint probability distribution $f\left(\mathrm{x}_{t+1} \mid \Omega_{t}\right)$ can be derived by the aggregation of the individual subjective probability distributions, where $\Omega_{t}$ is the information set at time $t$, and

\footnotetext{
${ }^{7}$ The procedure explained in this section is not the same as the original by Carlson and Parkin (1975), but it is in line with the slightly modified versions of Henzel and Wollmershäuser (2006), Hori and Terai (2005), Oral (2013), and Scheufele (2011).
} 
$\mathrm{x}_{t+1}$ is the future change in prices in percentage at time $t$ for the period $t+1$. This distribution is assumed to have finite firstand second-order moments, and to be expressed as $E\left[\mathrm{x}_{t+1} \mid \Omega_{t}\right]=\pi_{t+1}^{\mathrm{e}}$, where $\pi_{t+1}^{\mathrm{e}}$ is the inflation expectation for the period $t+1$. Further, it is assumed that there exists an interval $\left(-\delta_{t}, \delta_{t}\right)$ around $0\left(\delta_{t}>0\right)$ such that the respondents report "no change" in prices if the expected price change lies within this interval. With this $\delta_{t}$, threshold, respondents are supposed to express their expectations of price changes in the following manner:

$$
\begin{gathered}
\text { "prices up" if } \pi_{t+1}^{\mathrm{e}}>\delta_{t} . \\
\text { "prices down" if } \pi_{t+1}^{\mathrm{e}}<-\delta_{t} . \\
\text { "no change" if }-\delta_{t} \leq \pi_{t+1}^{\mathrm{e}} \leq \delta_{t} .
\end{gathered}
$$

The respondents' report reflects an individual probability distribution over the possible future values of the variable in question and a sampling from some aggregate distribution. Thus, the ratio (or percentage) of the "prices up" responses, denoted by " $\mathrm{U}_{t}$," and "prices down" responses, denoted by " $\mathrm{D}_{t}$," are transformed into the following population values:

$$
\begin{gathered}
\mathrm{U}_{t}=1-\Phi\left(\frac{\delta_{t}-\mu_{t}}{\sigma_{t}}\right), \\
\mathrm{D}_{t}=\Phi\left(\frac{-\delta_{t}-\mu_{t}}{\sigma_{t}}\right),
\end{gathered}
$$

where $\Phi$ is the cumulative distribution function of the standard normal distribution, and $\mu_{t}$ and $\sigma_{t}$ are the mean and the standard deviation of the aggregate distribution of the inflation expectation, respectively. With these two equations, we have

$$
\begin{gathered}
a_{t}=\Phi^{-1}\left(1-\mathrm{U}_{t}\right)=\left(\frac{\delta_{t}-\mu_{t}}{\sigma_{t}}\right), \\
b_{t}=\Phi^{-1}\left(\mathrm{D}_{t}\right)=\left(\frac{-\delta_{t}-\mu_{t}}{\sigma_{t}}\right),
\end{gathered}
$$

where $\Phi^{-1}$ is the inverse function of $\Phi$. Consequently, $\mu_{t}$ and $\sigma_{t}$ are solved as

$$
\begin{aligned}
& \mu_{t}=-\delta_{t}\left(\frac{a_{t}+b_{t}}{a_{t}-b_{t}}\right), \\
& \sigma_{t}=2 \delta_{t}\left(\frac{1}{a_{t}-b_{t}}\right),
\end{aligned}
$$

if we have $\delta_{t}$. One simple way to obtain the plausible value of $\delta_{t}$ is to assume a constant $\delta$ (i.e., $\delta_{t}=\delta$ ) and

$$
\sum_{t=1}^{\mathrm{T}} \pi_{t}=\sum_{t=1}^{\mathrm{T}} \mu_{t}
$$

where $\pi_{t}$ is the observed inflation rate. With this assumption, we have

$$
\delta=-\frac{\sum_{t=1}^{\mathrm{T}} \pi_{t}}{\sum_{t=1}^{\mathrm{T}}\left(\frac{a_{t}+b_{t}}{a_{t}-b_{t}}\right)} .
$$

Substituting this $\delta$ into (28) and (29), we obtain $\mu_{\mathrm{t}}$, the expected inflation rate (as a kind of mean value of the inflation expectation) and $\sigma_{t}$, the standard deviation.

Despite the usefulness of the Carlson-Parkin method, some problems have been pointed out. For example, the thresholds might be asymmetric between the expectations of "prices up" and "prices down," although the Carlson-Parkin model assumes they are symmetric. To cope with this issue, Kanoh $(2006)^{8}$ (in Japanese) proposes an extended methodology that has the two kinds of thresholds: $\delta_{1}$ for "prices up" and $\delta_{2}$ for "prices down." The modifications by Kanoh (2006) are as follows.

Respondents are supposed to express an expectation of the price change as follows:

$$
\begin{aligned}
& \text { "prices up" if } \pi_{t+1}^{\mathrm{e}}>\delta_{1} . \\
& \text { "prices down" if } \pi_{t+1}^{\mathrm{e}}<\delta_{2} . \\
& \text { "no change" if } \delta_{2} \leq \pi_{t+1}^{\mathrm{e}} \leq \delta_{1} .
\end{aligned}
$$

For the mean and the variance of the expectation series, the assumption

$$
\sum_{t=1}^{\mathrm{T}} \sigma_{t}^{2}=\sum_{t=1}^{\mathrm{T}}\left(\pi_{t}-\bar{\pi}\right)^{2}
$$

where $\bar{\pi}$ is the average of the observed inflation rate, is appended. With this additional assumption, equations (28) and (29) are altered as

$$
\begin{gathered}
\mu_{t}=\left(\frac{a_{t} \delta_{2}-b_{t} \delta_{1}}{a_{t}-b_{t}}\right), \\
\sigma_{t}=\left(\frac{\delta_{1}-\delta_{2}}{a_{t}-b_{t}}\right),
\end{gathered}
$$

if we assume $\delta_{1}$ and $\delta_{2}$ are constant, namely, $\delta_{1 t}=\delta_{1}$ and $\delta_{2 t}=\delta_{2}$. After some algebraic manipulation following the above procedures, we have ${ }^{9}$

$$
\begin{gathered}
\delta_{1}=\frac{1}{\mathrm{~T}}\left(\sum_{t=1}^{\mathrm{T}} \pi_{t}+\sum_{t=1}^{\mathrm{T}} \frac{a_{t}}{a_{t}-b_{t}} \sqrt{\frac{\sum_{t=1}^{\mathrm{T}}\left(\pi_{t}-\bar{\pi}\right)^{2}}{\sum_{t=1}^{\mathrm{T}}\left(\frac{1}{a_{t}-b_{t}}\right)^{2}}}\right), \\
\delta_{2}=\frac{1}{\mathrm{~T}}\left(\sum_{t=1}^{\mathrm{T}} \pi_{t}+\sum_{t=1}^{\mathrm{T}} \frac{b_{t}}{a_{t}-b_{t}} \sqrt{\frac{\sum_{t=1}^{\mathrm{T}}\left(\pi_{t}-\bar{\pi}\right)^{2}}{\sum_{t=1}^{\mathrm{T}}\left(\frac{1}{a_{t}-b_{t}}\right)^{2}}}\right) .
\end{gathered}
$$

Plugging (38) and (39) into (36) and (37), we obtain $\mu_{t}$ and $\sigma_{t}$, respectively.

\subsection{Application of the "Tankan" (Short-term Economic Survey of Enterprises in Japan) to the Estimations of Expected Inflation}

The "Tankan" (Short-term Economic Survey of Enterprises in Japan $)^{10}$ is conducted by the Bank of Japan. It is one of the applicable data sources for the Carlson-Parkin-type approach. This survey is conducted on a quarterly basis to investigate the business trends of Japanese enterprises, contributing to the

\footnotetext{
${ }^{8}$ Kanoh (2006) proposes some methods for the estimation of inflation expectations in Chapter 2 and Chapter 3. The method applied in this paper is explained in Chapter 2, Section 3 of Kanoh (2006).

${ }^{9}$ Kanoh (2006) gives only a verbal explanation of his modification, with no concrete derivation process for equations (38) and (39). However, following the given assumptions and the conditions, we can calculate these equations.

${ }^{10}$ See "https://www.boj.or.jp/en/statistics/outline/exp/tk/faqtk03.htm/" for details.
} 
formation of relevant monetary policy. The participants are approximately 210000 large private enterprises (excluding financial institutions). The results of the survey are released regularly.

For our estimation of the inflation expectation by the private enterprises based on the Kanoh's (2006) methodology, the qualitative data on "change in output prices" in the "Judgement Survey" section of the "Tankan" can be applied. For the item "change in output prices," respondents give their perceptions of the past and future movements of the selling prices of major products and services on the quarterly basis by choosing from "rise," "no change," and "fall" as the best way to recognize prevailing changes from three months earlier and three months ahead. Thus, the data on "rise" and "fall" in the next three months for "change in output prices" can be utilized for our estimation.

\section{Empirical Results}

In this section, we conduct the estimations of the hybrid New Keynesian Phillips Curve (hybrid NKPC) with the observed inflation rate in the corporate goods price index (CGPI) ${ }^{11}$ and of the one with the estimated firm-level expected inflation rate in order to examine inflation dynamics in Japan. The firm-level expected inflation rate is estimated by the Kanoh (2006)-type extended Carlson-Parkin method.

Our estimations are related to the discussion of monetary policy and its implications. For instance, discussion of monetary policy must include a certain degree of emphasis on the backward-looking factor in addition to the forward-looking element, although the forward guidance policy by the central banks is a recent important topic. In fact, the identification of the backward-looking factor for the price level and inflation is a significant concern in monetary policy formation in that it can help explain inflation persistence and the costs of disinflation processes. Further, if there is a chance that firms' inflation expectations are not always as exact as those assumed by the rational expectations hypothesis, the central bank should take this problem into consideration in designing monetary policy. Moreover, if flattening of the New Keynesian Phillips Curve is detected, inflation will less responsive to movements in aggregate economic activities such as the output gap. This affects the credibility implications of monetary policy. From these points of view, our estimations can provide a basis upon which to examine the policy making of central banks

The sample periods for our estimations are monthly, 1994:M01 - 2014:M12, for the Kanoh (2006)-type extended Carlson-Parkin method and quarterly, 1994:Q1 - 2014:Q4, for the hybrid NKPC. The reason for choosing this period is that the long-run time series data on "GDP" and "compensation of employees" from Japan's latest System of National Accounts (SNA) are available from the first quarter of 1994. The data set for our empirical study is constructed as follows. $^{12}$

\footnotetext{
${ }^{11}$ Japan's corporate goods price index (CGPI) is regarded as a kind of producer price index (PPI)

12 The data on "GDP," and "compensation of employees" were obtained from the
}

At: Percentage share for "rise" (Tankan, judgement survey, change in output prices, answer 1, all enterprises, all industries, forecast, averaged)

Bt: Percentage share for "fall" (Tankan, judgement survey, change in output prices, answer 3 , all enterprises, all industries, forecast, averaged)

Gp: Nominal GDP (original series, quarterly estimates, first preliminary, ${ }^{13}$ billion yen)

$\mathrm{Cn}$ : Compensation of employees (original series, quarterly estimates, first preliminary, ${ }^{14}$ billion yen)

Pi: Corporate goods price index (all commodities, monthly, CY2010 average $=100)$

Ee: Employee (monthly, all of Japan, total)

Ep: Employed persons (monthly, all of Japan, total)

$\mathrm{Cp}$ : Compensation of employed persons $=(\mathrm{Cn} / \mathrm{Ee}) \mathrm{Ep}$ ("Ee" and "Ep" are converted from monthly to quarterly series.)

Ls: Labor share $(=\mathrm{Cp} / \mathrm{Gp})$

Lt: Trend component of Ls obtained by the HodrickPrescott filter, ${ }^{15}$ setting the penalty parameter $=1600$

Lc: Proxy variable for $\widehat{m c}(=\hat{s})=\log (\mathrm{Ls})-\log (\mathrm{Lt})$

$\widehat{\mu_{t}}$ : Estimated expected inflation rate by the Kanoh (2006) -type extended Carlson-Parkin method

The monthly data for "corporate goods price index," "employee," and "employed persons" are converted into quarterly series by taking the three-months averages for our estimation. Concerning the inflation measure (based on the corporate goods price index), we adopt the backward-moving average of quarterly inflation, $\pi_{t}^{*}=(1 / 4) \sum_{i=0}^{3} \pi_{t-i}$, where $\pi_{t}$ is the inflation rate at time $t$, as the change from the previous quarter of the corporate goods price index. A problem with estimating the hybrid New Keynesian Phillips Curve, $\pi_{t}=\gamma_{b} \pi_{t-1}+\gamma_{f} E_{t}\left[\pi_{t+1}\right]+\lambda \widehat{m c}_{t}$, is how to obtain $\widehat{m c}_{t}$ (the proxy for the marginal cost). Following Section 2.1, we use the labor share (Ls), and its trend component (Lt) (obtained via the Hodrick-Prescott filter) is regarded as the proxy for the steady-state value. Then, we utilize "Lc" in the above data set as $\widehat{m c}$. Another problem is the correlation due to the causal relationship between the variables. The unobservable expected inflation $E_{t}\left[\pi_{t+1}\right]$ is replaced by the actually observed $\pi_{t+1}$ under the assumption of rational expectations in our first estimation, and by the estimated expected inflation rate: $\widehat{\mu_{t}}$ (based on the Kanoh's (2006) methodology) in our second estimation. However, this treatment may cause correlation between the explanatory variables and the error term. To deal with this problem,

Economic and Social Research Institute, Cabinet Office's website (in English): "http://www.esri.cao.go.jp/index-e.html". The "employee," and "employed persons" data were retrieved from the "Portal Site" of Official Statistics of Japan, which is administered by the Ministry of Internal Affairs and Communications, Statistics Bureau, Director-General for Policy Planning (Statistical Standards) \& Statistical Research and Training Institute (in English): "http://www.e-stat.go.jp/ SG1/estat/eStatTopPortalE.do". The data on "percentage share for rise," "percentage share for fall," and "corporate goods price index" were obtained from the website of the Bank of Japan (in English): "https://www.boj.or.jp/en/ statistics/index.htm/".

${ }^{13}$ Released on February 16, 2015.

${ }^{14}$ Released on February 16, 2015.

${ }^{15}$ See Hodrick and Prescott (1997) for the concrete discussion. For a concise explanation, see Chapter 2 of Mark (2001). 
generalized method of moments (GMM) is adopted for our estimation. In addition, our GMM estimations are conducted with the Newey-West HAC (Heteroscedasticity and Autocorrelation Consistent) weighting matrix to obtain the robust standard errors. Moreover, since we must take a critical stance toward GMM estimation because of the problem of weak identification, we conduct the Hansen test for over-identification, the C-test for instrumental variables' orthogonality, and the test utilizing the Cragg-Donald statistic and the Stock-Yogo critical values.

The reduced-form coefficient $\lambda$ expressed in equation (20) is a function of $\beta, \omega, \theta, \alpha$, and $\varepsilon$, but we cannot estimate all these structural parameters because of the identification restrictions. One plausible estimation strategy is as follows. Let us define $\varphi \equiv \frac{1-\alpha}{1+\alpha(\varepsilon-1)} \in(0,1)$ as a function of $\alpha$ and $\varepsilon$. Next, suppose a special case of the constant $\varphi$, that is, the case of constant returns to scale or constant marginal costs across firms. ${ }^{16}$ Following Galí, Gertler, and López-Salido (2001) and Maturu, Kisinguh, and Maana (2007), we regard $\varphi$ as 1 . Plugging $\varphi=1$ into equation (20), we have

$$
\bar{\lambda} \equiv(1-\omega)(1-\theta)(1-\beta \theta) \emptyset^{-1} \text {. }
$$

Given this revision, the specification of the hybrid New Keynesian Phillips curve for our estimation is described as:

$$
\pi_{t}=\gamma_{b} \pi_{t-1}+\gamma_{f} E_{t}\left[\pi_{t+1}\right]+\bar{\lambda} \widehat{m c}_{t}
$$

where

$$
\begin{gathered}
\gamma_{b}=\omega \emptyset^{-1}, \\
\gamma_{f}=\beta \theta \emptyset^{-1}, \\
\emptyset=\theta+\omega[1-\theta(1-\beta)], \\
\bar{\lambda} \equiv(1-\omega)(1-\theta)(1-\beta \theta) \emptyset^{-1} .
\end{gathered}
$$

With this specification, we are able to estimate the reduced-form parameters $\gamma_{b}, \gamma_{f}$, and $\bar{\lambda}$ as well as the structural parameters $\omega, \theta$, and $\beta$. The corresponding orthogonality condition for our GMM estimation is constructed as

$$
E_{t}\left[\left\{\begin{array}{c}
\pi_{t}-\omega \emptyset^{-1} \pi_{t-1}-\beta \theta \emptyset^{-1} \pi_{t+1} \\
-(1-\omega)(1-\theta)(1-\beta \theta) \emptyset^{-1} \widehat{m c}_{t}
\end{array}\right\} Z_{t}\right]=0
$$

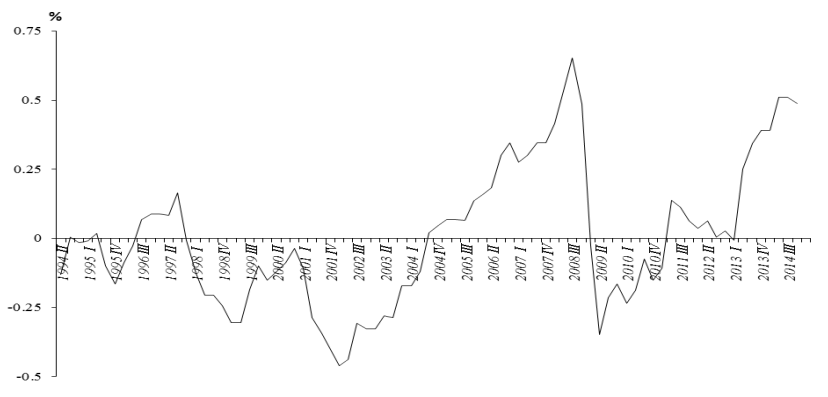

Figure 1. Estimated Firm-level Expected Inflation Rate in Japan by the Kanoh (2006)-type extended Carlson-Parkin method: Quarterly Rate (based on the Corporate Goods Price Index)

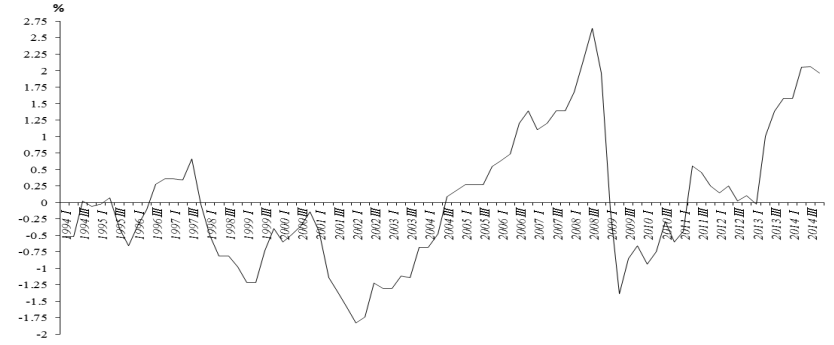

Figure 2. Estimated Firm-level Expected Inflation Rate in Japan by the Kanoh (2006)-type extended Carlson-Parkin method: Annualized Quarterly Rate (based on the Corporate Goods Price Index)

where $Z_{t}$ denotes the vector of the instrumental variables. The instrumental variables included in our $Z_{t}$ are those listed in Tables 1-3 and 2-3 (with the results of the orthogonality C-Tests) in addition to the constant terms.

The estimation of the expected inflation rate is implemented by the Kanoh (2006)-type extended Carlson-Parkin method explained in section 3.2. We utilize the qualitative data obtained from the "Tankan". Concretely, "At" and "Bt" in the above data set correspond to " $a_{t}$ " and " $b_{t}$ " in equations (36) and (37), respectively. Two kinds of thresholds, $\widehat{\delta_{1}}=1.5873$ and $\widehat{\delta_{2}}=-0.6619$, are estimated with $\widehat{\mu_{t}}$. These imply that Japanese corporations (survey participants) report a "rise" if the expected price change in next three months is at least $1.59 \%$ higher, and report a "fall" if the expected price change is at least $0.66 \%$ smaller. Figure 1 reports the estimated quarterly firm-level expected inflation rate, and this data series is applied to our second estimation of the hybrid NKPC as $E_{t}\left[\pi_{t+1}\right]$. Figure 2 displays its annualized rate.

Table 1-1 displays the estimation results of the hybrid NKPC using the observed $\pi_{t+1}$ as the proxy for $E_{t}\left[\pi_{t+1}\right]$ under the assumption of rational expectations. Concerning the diagnostic tests, the null hypotheses of over-identification for the GMM estimations for reduced-form and structural parameters cannot be rejected by the Hansen tests, which supports the validity of the moment conditions, as shown by the $J$-statistics and $p$-values in the notes under the table. With regard to the reduced-form parameters, the estimates of $\gamma_{b}$ for lagged inflation and $\gamma_{f}$ for future inflation are both significant. In addition, the sum of $\gamma_{b}$ and $\gamma_{f}$ seems to be close to 1 , the theoretical value. The null hypothesis of the equality restriction test $\left(\gamma_{b}+\gamma_{f}=1\right)$ cannot be rejected, as indicated in Table 1-2. The fact that the estimated value of $\gamma_{b}$ is larger than that of $\gamma_{f}$ implies the backward-looking behavior is comparatively predominant over the inflation dynamics (based on the inflation rate in the corporate goods

\footnotetext{
${ }^{16}$ In this case, capital is assumed to be freely mobile across firms.
} 
Table 1-1. GMM Estimation with Observed Inflation Term

\begin{tabular}{clcc}
\hline reduced-form parameter & & & \\
\hline variable & coefficient & standard error & $\boldsymbol{p}$-value \\
\hline$\gamma_{b}$ & 0.535252 & 0.026537 & 0.0000 \\
$\gamma_{f}$ (observed) & 0.447384 & 0.034741 & 0.0000 \\
$\bar{\lambda}$ & 0.067164 & 0.097154 & 0.4915 \\
\hline structural parameter & & & p-value \\
\hline variable & coefficient & standard error & 0.0007 \\
\hline$\omega$ & 0.621186 & 0.176397 & 0.0041 \\
$\beta$ & 0.572096 & 0.193521 & 0.0000 \\
\hline duration (in quarters) & 0.907225 & 0.147370 & \\
\hline
\end{tabular}

Notes (reduced-form parameter): Standard errors of regression $=0.181599 . J$-statistic $=4.810690, p$-value $(J$-statistic $)=0.568313$, Included observations $=79$ (after adjustments). Estimation weighting matrix: HAC (Bartlett kernel, Newey-West fixed bandwidth $=4$ ). Standard errors and covariance computed using HAC weighting matrix (Bartlett kernel, Newey-West fixed bandwidth $=4$ ). Convergence achieved after 32 weight iterations.

Notes (structural parameter): Standard errors of regression $=0.181600 . J$-statistic $=4.810526, p$-value $(J$-statistic $)=0.568334$, Included observations $=79($ after adjustments). Estimation weighting matrix: HAC (Bartlett kernel, Newey-West fixed bandwidth $=4$ ). Standard errors and covariance computed using HAC weighting matrix (Bartlett kernel, Newey-West fixed bandwidth $=4$ ). Convergence achieved after 94 coefficient and 35 weight iterations.

Table 1-2. Equality Restriction Test for Reduced-form Parameter

\begin{tabular}{cccc}
\hline null hypothesis: $\gamma_{\boldsymbol{b}}+\gamma_{\boldsymbol{f}}=\mathbf{1}$ & & \\
\hline Test Statistic & Value & d.f. & $\boldsymbol{p}$-value \\
\hline$F$ & 0.389107 & $(1,76)$ & 0.5346 \\
$\chi^{2}$ & 0.389107 & 1 & 0.5328 \\
\hline
\end{tabular}

Table 1-3. Orthogonality C-Test for Instrumental Variables

\begin{tabular}{|c|c|c|c|c|c|}
\hline \multicolumn{6}{|c|}{ reduced-form parameter estimation } \\
\hline \multirow{2}{*}{ Test instruments } & \multicolumn{3}{|c|}{ Difference in $J$-stats } & \multirow{2}{*}{$\begin{array}{l}\text { Restricted } \\
J \text {-statistic }\end{array}$} & \multirow{2}{*}{$\begin{array}{l}\text { Unrestricted } \\
J \text {-statistic }\end{array}$} \\
\hline & Value & d.f. & p-value & & \\
\hline inflation(-1) & 0.890876 & 1 & 0.3452 & 4.810690 & 3.919814 \\
\hline inflation(-2) & 0.732191 & 1 & 0.3922 & 4.810690 & 4.078499 \\
\hline inflation(-3) & 0.824277 & 1 & 0.3639 & 4.810690 & 3.986413 \\
\hline inflation(-4) & 1.632715 & 1 & 0.2013 & 4.810690 & 3.177975 \\
\hline marginal cost(-1) & 0.103277 & 1 & 0.7479 & 4.810690 & 4.707413 \\
\hline marginal cost $(-2)$ & 0.292594 & 1 & 0.5886 & 4.810690 & 4.518096 \\
\hline marginal cost $(-3)$ & 0.550014 & 1 & 0.4583 & 4.810690 & 4.260676 \\
\hline marginal cost $(-4)$ & 0.699945 & 1 & 0.4028 & 4.810690 & 4.110745 \\
\hline \multicolumn{6}{|c|}{ structural parameter estimation } \\
\hline \multirow{2}{*}{ Test instruments } & \multicolumn{3}{|c|}{ Difference in $J$-stats } & \multirow{2}{*}{$\begin{array}{l}\text { Restricted } \\
J \text {-statistic } \\
\end{array}$} & \multirow{2}{*}{$\begin{array}{l}\text { Unrestricted } \\
J \text {-statistic }\end{array}$} \\
\hline & Value & d.f. & p-value & & \\
\hline inflation(-1) & 0.889670 & 1 & 0.3456 & 4.810526 & 3.920855 \\
\hline inflation(-2) & 0.731137 & 1 & 0.3925 & 4.810526 & 4.079389 \\
\hline inflation(-3) & 0.823402 & 1 & 0.3642 & 4.810526 & 3.987124 \\
\hline inflation(-4) & 1.632553 & 1 & 0.2014 & 4.810526 & 3.177973 \\
\hline marginal cost $(-1)$ & 0.292336 & 1 & 0.7479 & 4.810526 & 4.707233 \\
\hline marginal cost $(-2)$ & 0.292336 & 1 & 0.5887 & 4.810526 & 4.518190 \\
\hline marginal cost $(-3)$ & 0.549443 & 1 & 0.4585 & 4.810526 & 4.261083 \\
\hline marginal cost(-4) & 0.678961 & 1 & 0.4099 & 4.810526 & 4.131564 \\
\hline
\end{tabular}


Table 1-4. Weak Instrument Diagnostics (reduced-form parameter estimation)

\begin{tabular}{lrr}
\hline Cragg-Donald $\boldsymbol{F}$-statistic & $\mathbf{1 0 . 2 1 6 7 7}$ \\
\hline & $5 \%$ & 17.70 \\
Stock-Yogo critical values & $10 \%$ & 10.22 \\
(relative bias) & $20 \%$ & 6.20 \\
& $30 \%$ & 4.73 \\
\hline & $10 \%$ & 25.64 \\
Stock-Yogo critical values & $15 \%$ & 14.31 \\
(size) & $20 \%$ & 10.41 \\
& $25 \%$ & 8.39 \\
\hline
\end{tabular}

price index) during the sample period. The coefficient $\bar{\lambda}$ on the marginal cost is not significant, which might imply that marginal cost is not an effective indicator of inflation. $\bar{\lambda}$ can also be regarded as the slope coefficient of NKPC. In this regard, the hybrid NKPC we focus on is very flat since the estimated value of $\bar{\lambda}$ is very small (and insignificant).

The structural parameter $\omega$, the degree of backwardness in price setting, is significant. This result is in line with the significance of $\gamma_{b}$ in the reduced-form estimation. The parameter $\theta$, the measure of price stickiness (or the fraction of firms that keeps prices constant), is also estimated to be significant. The average duration of a price remaining fixed (explained in section 2.1) corresponding to the estimate of $\theta$ (in quarters) is 2.336973. In other words, price adjustment occurs approximately every 7 months during our sample period. The estimated value of the discount factor $\beta$ is 0.907225 , which is slightly smaller than the theoretical value, $0.99 .^{17}$

Table 1-3 reports the results of the orthogonality C-tests for each instrumental variable except the constant term. In short, the tests that detect whether each instrumental variable satisfies the orthogonality condition are implemented individually. The results suggest that the null hypotheses of each instrumental variable's orthogonality to the error term cannot be rejected at the conventional level for all cases.

Further, to investigate the weak identification problem raised in some studies, including Mavroeidis (2004), we utilize the Cragg and Donald (1993) statistic and the Stock and Yogo (2005) critical values. ${ }^{18}$ In Table 1-4, the Cragg-Donald F-statistic for reduced-form parameter estimation is smaller than the Stock-Yogo critical values for both relative bias and size. It means that the null hypothesis that the equation is weakly identified cannot be rejected at the conventional level. Therefore, the test result implies that we have weak instruments. ${ }^{19}$

Table 2-1 indicates the results of the estimations utilizing $\mu_{t}$ obtained by the Kanoh (2006)-type extended Carlson-Parkin method as the proxy for $E_{t}\left[\pi_{t+1}\right]$. The null hypotheses of over-identification for the GMM estimations cannot be rejected by the Hansen tests, as described by the $J$-statistics and $p$-values in the notes under the table.

\footnotetext{
${ }^{17}$ For instance, Christiano, Eichenbaum, and Evans (2005) regard $\beta$ as $\beta=$ $1.03-0.25$. This can be interpreted as $\beta=1.03-0.25 \approx 0.99$. Erceg, Henderson, and Levin (2000), Giannoni and Woodford (2003), Steinsson (2003), Walsh (2003), and Christiano, Eichenbaum, and Evans (2005) also assume $\beta=0.99$.

${ }^{18}$ See Cragg and Donald (1993), Stock, Wright, and Yogo (2002), and Stock and Yogo (2005) for details.

${ }^{19}$ The Stock-Yogo critical values for the structural parameter estimation cannot be calculated because of the nonlinearity of the estimation specification.
}

Concerning the reduced-form parameters, $\gamma_{b}$ is estimated to be significant at the $1 \%$ level, and $\gamma_{f}$ is significant at $5 \%$. The total sum of these values seems to exceed 1. By the equality restriction test, however, the null hypothesis of $\gamma_{b}+\gamma_{f}=1$ cannot be rejected as indicated in Table 2-2. The value of $\gamma_{b}$ is considerably larger than that of $\gamma_{f}$, indicating that the backward-looking factor has a larger impact on shaping inflation dynamics than the forward-looking one. The insignificance and negative sign of the coefficient estimated on $\bar{\lambda}$ suggests that the impact of the marginal cost on the inflationary process is not sufficient. At the same time, the estimated small value of $\bar{\lambda}$ implies a very flat NKPC.

With regard to the structural parameters, the estimated coefficient on $\omega$ is significant, while that on $\theta$ is insignificant. However, if we consider the duration problem for reference, we find that the estimated larger value of $\theta$ compared with that obtained in the case of rational expectations assumption (displayed in Table 1-1) leads to the longer average duration of price adjustment around 3.64 quarters. This value suggests that prices remain unchanged for roughly 11 months. This long duration might reflect the prolonged Japanese recession after the collapse of the bubble economy. Next, the estimate of $\beta$, the discount factor, is significant, but it has a negative sign. This result might suggest that the degree of rationality of the firm-level inflation expectations is insufficient.

Table 2-3 displays the results of the orthogonality tests for the instrumental variables except the constant term. The test statistics suggest that the null hypotheses of each instrumental variable's orthogonality cannot be rejected for all cases at the standard level. Namely, the tests show that the instrumental variables applied to the estimation satisfy the orthogonality conditions.

Table 2-4 reports the weak identification diagnostics with respect to the estimation of the reduced-form parameters. As this table shows, the Cragg-Donald F-statistic is larger than the two kinds of Stock-Yogo (2005) critical values, rejecting the null hypothesis of weak identification. This suggests that our instrumental variables are not weak.

By comparing the estimation result with the observed future inflation rate and that with the estimated firm-level expected inflation rate, we find some points to consider. First, the reduced-form coefficients on $\gamma_{b}$ are significant in both the former case and the latter case. Second, the significances of the structural parameters $\omega$ in both cases and $\theta$ in the former case are consistent with the results of $\gamma_{b}$, in that the backward-looking factor has a certain impact on the inflation 
dynamics. Third, the coefficients on $\gamma_{f}$ are estimated to be significant in both cases. Fourth, the coefficient on the estimated expected future inflation is significant in the latter case, but its level of significance $(5 \%)$ is lower than that of the observed future inflation $(1 \%)$ in the former case. Moreover, the standard error of the coefficient on the estimated expected future inflation term $(0.204992)$ is much larger than that of the observed future inflation term (0.034741). Lastly, the small estimated values of $\bar{\lambda}$ in the two cases of estimation imply a very flat NKPC in Japan recently.

\section{Concluding Remarks}

This paper examines inflation dynamics in Japan through estimations of the hybrid New Keynesian Phillips Curve. The estimation with the observed inflation rate in the corporate

Table 2-1. GMM Estimation with Estimated Expected Inflation Term

\begin{tabular}{cccc}
\hline reduced-form parameter & & & \\
\hline variable & coefficient & standard error & p-value \\
\hline$\gamma_{b}$ expected) & 0.752573 & 0.071795 & 0.0000 \\
$\bar{\lambda}$ & 0.411357 & 0.204992 & 0.0483 \\
\hline structural parameter & -0.117411 & 0.214728 & 0.5861 \\
\hline variable & & & standard error \\
\hline$\omega$ & coefficient & 0.084580 & 0.0000 \\
\hline$\beta$ & 0.714110 & 0.440644 & 0.1038 \\
\hline duration (in quarters) & 0.725277 & 0.331395 & \\
\hline
\end{tabular}

Notes (reduced-form parameter): Standard errors of regression $=0.333460 . J$-statistic $=7.107150, p$-value $(J$-statistic $)=0.525117$, Included observations $=80$ (after adjustments). Estimation weighting matrix: HAC (Bartlett kernel, Newey-West fixed bandwidth $=4$ ). Standard errors and covariance computed using HAC weighting matrix (Bartlett kernel, Newey-West fixed bandwidth $=4$ ). Convergence achieved after 52 weight iterations.

Notes (structural parameter): Standard errors of regression $=0.378073 . J$-statistic $=0.758409, p$-value $(J$-statistic $)=0.684406$, Included observations $=81$ (after adjustments). Estimation weighting matrix: HAC (Bartlett kernel, Newey-West fixed bandwidth $=4$ ). Standard errors and covariance computed using HAC weighting matrix (Bartlett kernel, Newey-West fixed bandwidth $=4$ ). Convergence achieved after 18 coefficient and 6 weight iterations.

Table 2-2. Equality Restriction Test for Reduced-form Parameter

\begin{tabular}{cccc}
\hline null hypothesis: $\gamma_{\boldsymbol{b}}+\gamma_{\boldsymbol{f}}=\mathbf{1}$ & & \\
\hline Test Statistic & Value & d.f. & $\boldsymbol{p}$-value \\
\hline$F$ & 1.063967 & $(1,77)$ & 0.3055 \\
$\chi^{2}$ & 1.063967 & 1 & 0.3023 \\
\hline
\end{tabular}

Table 2-3. Orthogonality C-Test for Instrumental Variables

\begin{tabular}{|c|c|c|c|c|c|}
\hline \multicolumn{6}{|c|}{ reduced-form parameter estimation } \\
\hline \multirow{2}{*}{ Test instruments } & \multicolumn{3}{|c|}{ Difference in $J$-stats } & \multirow{2}{*}{$\begin{array}{l}\text { Restricted } \\
J \text {-statistic }\end{array}$} & \multirow{2}{*}{$\begin{array}{l}\text { Unrestricted } \\
J \text {-statistic }\end{array}$} \\
\hline & Value & d.f. & p-value & & \\
\hline inflation(-1) & 0.458596 & 1 & 0.4983 & 7.107150 & 6.648554 \\
\hline inflation(-2) & 0.009370 & 1 & 0.9229 & 7.107150 & 6.648554 \\
\hline inflation(-3) & 0.122885 & 1 & 0.7259 & 7.107150 & 6.648554 \\
\hline inflation(-4) & 0.255662 & 1 & 0.6131 & 7.107150 & 6.648554 \\
\hline marginal cost(-1) & 0.311617 & 1 & 0.5767 & 7.107150 & 6.648554 \\
\hline marginal cost(-2) & 0.244974 & 1 & 0.6206 & 7.107150 & 6.648554 \\
\hline marginal cost(-3) & 0.276491 & 1 & 0.5990 & 7.107150 & 6.648554 \\
\hline expected inflation & 0.105646 & 1 & 0.7452 & 7.107150 & 6.648554 \\
\hline expected inflation(-1) & 0.031612 & 1 & 0.8589 & 7.107150 & 6.648554 \\
\hline \multicolumn{6}{|c|}{ structural parameter estimation } \\
\hline \multirow{2}{*}{ Test instruments } & \multicolumn{3}{|c|}{ Difference in $J$-stats } & \multirow{2}{*}{$\begin{array}{l}\text { Restricted } \\
J \text {-statistic }\end{array}$} & \multirow{2}{*}{$\begin{array}{l}\text { Unrestricted } \\
J \text {-statistic }\end{array}$} \\
\hline & Value & d.f. & p-value & & \\
\hline marginal cost(-1) & 0.718463 & 1 & 0.3966 & 0.758409 & 0.039945 \\
\hline marginal cost(-2) & 0.615687 & 1 & 0.4327 & 0.758409 & 0.142721 \\
\hline marginal cost(-3) & 0.720440 & 1 & 0.3960 & 0.758409 & 0.037968 \\
\hline expected inflation & 0.272445 & 1 & 0.6017 & 0.758409 & 0.485964 \\
\hline
\end{tabular}


Table 2-4. Weak Instrument Diagnostics (reduced-form parameter estimation)

\begin{tabular}{lrr}
\hline Cragg-Donald $\boldsymbol{F}$-statistic & $\mathbf{2 6 9 . 4 6 2 9}$ \\
\hline & $5 \%$ & 20.53 \\
Stock-Yogo critical values & $10 \%$ & 11.46 \\
(relative bias) & $20 \%$ & 6.65 \\
& $30 \%$ & 4.92 \\
\hline & $10 \%$ & 36.19 \\
Stock-Yogo critical values & $15 \%$ & 19.71 \\
(size) & $20 \%$ & 14.01 \\
\end{tabular}

goods price index and that with the estimated firm-level expected inflation rate are considered. The firm-level expected inflation rate is estimated via the Kanoh (2006)-type extended Carlson-Parkin method. In addition, as the underlying points of interests, the validity of the pure forward-looking New Keynesian Phillips Curve and the implication with respect to the flattening of the hybrid New Keynesian Phillips Curve are considered.

Our empirical study leads us to the following conclusions. Firstly, the backward-looking factor has a dominant effect on inflation dynamics compared with the future element. Secondly, the forward-looking element has an unignorable impact on the inflation process even though it is weaker than the backward-looking factor. Thirdly, our result implies the incompleteness of the pure forward-looking New Keynesian Phillips Curve because of the significances of both the backward- and the forward-looking terms of our estimations of the hybrid New Keynesian Phillips Curve. This gives us the policy implication that the discussion of monetary policy has to place a certain emphasis on the backward-looking perspective in addition to the forward-looking view and must examine inflation persistence, although the forward guidance policy by the central banks is a recent important topic. Fourthly, the coefficient on the estimated expected future inflation is significant, but its level of significance is lower than that of the observed future inflation. Moreover, the standard error of the expected inflation term is much larger than that of the observed one. These two facts might imply that the degree of rationality of firm-level inflation expectations is insufficient. Namely, firms' inflation expectations might not always be as exact as the ones assumed by the rational expectations hypothesis, and the central bank should take this problem into consideration in the discussion on monetary policy design. Lastly, the estimated flattening of the New Keynesian Phillips Curve suggests that inflation would be less responsive to movements in the measures of aggregate economic activities, such as the output gap, and this topic is related to the credibility implications of monetary policy. This finding implies the Japanese central bank's current difficulty in conducting monetary policy.

\section{Acknowledgment}

This paper is dedicated to Professor Toshikazu Ito on the occasion of his retirement from Ryukoku University.

\section{References}

[1] Branch, William A. (2004), "The Theory of Rationally Heterogeneous Expectations: Evidence from Survey Data on Inflation Expectations," The Economic Journal, vol. 114, pp. 592-621.

[2] Brissimis, Sophocles, and Nicholas S. Magginas (2008), "Inflation Forecast and the New Keynesian Phillips Curve," International Journal of Central Banking, vol. 4(2), pp. 1-22.

[3] Calvo, Guillermo (1983), "Staggered Prices in a Utility Maximizing Framework," Journal of Monetary Economics, vol. 12(3), pp. 383-398.

[4] Carlson, John A., and Michael Parkin (1975), "Inflation Expectations," Economica, vol. 42(166), pp. 123-138.

[5] Carroll, Christopher D. (2003), "Macroeconomic Expectations of Households and Professional Forecasters," The Quarterly Journal of Economics, vol. 118(1), pp. 269-298.

[6] Christiano, Lawrence, Eichenbaum, Martin, and Charles Evans (2001), "Nominal Rigidities and the Dynamic Effects of a Shock to Monetary Policy," NBER Working Paper Series, no. 8403.

[7] Christiano, Lawrence, Eichenbaum, Martin, and Charles Evans (2005), "Nominal Rigidities and the Dynamic Effects of a Shock to Monetary Policy," Journal of Political Economy, vol. 113(1), pp. 1-45.

[8] Clarida, Richard, Galí, Jordi, and Mark Gertler (1999), "The Science of Monetary Policy: A New Keynesian Perspective," Journal of Economic Literature, vol. 37(4), pp. 1661-1707.

[9] Cragg, John G., and Stephen G. Donald (1993), "Testing Identifiability and Specification in Instrumental Variables Models," Economic Theory, vol. 9(2), pp. 222-240.

[10] Erceg, Christopher, Henderson, Dale, and Andrew Levin (2000), "Optimal Monetary Policy with Staggered Wage and Price Contracts," Journal of Monetary Economics, vol. 46(2), pp. 281-313.

[11] Evans, Martin, and Paul Wachtel (1992), "Inflation Regimes and the Sources of Inflation Uncertainty," Journal of Money, Credit and Banking, vol. 25(3)-2, pp. 475-511.

[12] Forsells, Magnus, and Geoff Kenny (2004), "The Rationality of Consumers' Inflation Expectations: Survey-Based Evidence for the Euro Area," European Central Bank Working Paper, no. 163.

[13] Gábriel, Péter (2010), "Household Inflation Expectations and Inflation Dynamics," MNB Working Papers, no. 2010/12. 
[14] Galí, Jordi (2008), Monetary Policy, Inflation, and the Business Cycle: An Introduction to the New Keynesian Framework, Princeton: Princeton University Press.

[15] Galí, Jordi, and Mark Gertler (1999), "Inflation Dynamics: A Structural Econometric Analysis," Journal of Monetary Economics, vol. 44(2), pp. 195-222.

[16] Galí, Jordi, Gertler, Mark, and David López-Salido (2001), "European Inflation Dynamics," European Economic Review, vol. 45(7), pp. 1237-1270.

[17] Galí, Jordi, Gertler, Mark, and David López-Salido (2005), "Robustness of the Estimates of the Hybrid New Keynesian Phillips Curve," Journal of Monetary Economics, vol. 52(6), pp. 1107-1118.

[18] Giannoni, Marc P., and Michael Woodford (2005), "Optimal Inflation-Targeting Rules," in Bernanke, Ben S., and Michael Woodford, eds., The Inflation-Targeting Debate, National Bureau of Economic Research, pp. 93-172.

[19] Goodfriend, Marvin, and Robert G. King (1997), "The New Neoclassical Synthesis and the Role of Monetary Policy," in Bernanke, Ben S., and Julio J. Rotemberg, eds., NBER Macroeconomics Annual 1997, vol. 12, Cambridge, MA: MIT Press, pp. 231-296.

[20] Henzel, Steffen, and Timo Wollmershäuser (2006), "Quantifying Inflation Expectations with the Carlson-Parkin Method - A Survey-Based Determination of the Just Noticeable Difference," Journal of Business Cycle Measurement and Analysis, Vol. 2005(3).

[21] Hodrick, Robert J., and Edward C. Prescott (1997), "Postwar U.S. Business Cycles: An Empirical Investigation," Journal of Money, Credit, and Banking, vol. 29(1), pp. 1-16.

[22] Hori, Masahiro, and Akira Terai (2005), "Carlson-Parkin Hou ni yoru Infurekitai no Keisoku to Syomondai” (in Japanese), Keizaibunseki (Economic and Social Research Institute, Japan), no. 175 , pp. 167-192.

[23] Kanoh, Satoru (2006), "Chapter 2: Survey Data no Teiryoka," (in Japanese) in Kanoh, Satoru, Macrokeizaibunseki to Survey Data, Tokyo: Iwanami Shoten, pp. 11-30.

[24] Kuester, Keith, Müller, Gernot J., and Sarah Stölting (2009), "Is the New Keynesian Phillips Curve Flat?" Economics Letters, vol. 103(1), pp. 39-41.

[25] Lindé, Jesper (2005), "Estimating New-Keynesian Phillips Curves: A Full Information Maximum Likelihood Approach," Journal of Monetary Economics, vol. 52(6), pp. 1135-1149.

[26] Mark, Nelson C. (2001), International Macroeconomics and Finance - Theory and Econometric Methods - , Oxford: Blackwell.

[27] Maturu, Benjamin, Kisinguh, Kethi, and Isaya Maana (2007), "A New Keynesian Phillips Curve for Kenya," paper presented at the 12th Annual Conference on Econometric Modeling for Africa organized by the African Econometric Society, held in Cape Town, South Africa, from 4th to 6th July 2007.

[28] Mavroeidis, Sophocles (2004), "Weak Identification of Forward-looking Models in Monetary Economics," Oxford Bulletin of Economics and Statistics, vol. 66(s1), pp. 609-635.

[29] Mazumder, Sandeep (2010), "The New Keynesian Phillips Curve and the Cyclicality of Marginal Cost," Journal of Macroeconomics, vol. 32(3), pp. 747-765.
[30] Newey, Whitney, and Kenneth West (1987), "A Simple, Positive Semi-definite, Heteroskedasticity and Autocorrelation Consistent Covariance Matrix," Econometrica, vol. 55(3), pp. 703-708.

[31] Oral, Ece (2013), "Consumer Inflation Expectations in Turkey," IFC Working Papers (Bank for International Settlements), no. 10.

[32] Rotemberg, Julio J. (1982a), "Sticky Prices in the United States," Journal of Political Economy, vol. 90(6), pp. $1187-1211$.

[33] Rotemberg, Julio J. (1982b), "Monopolistic Price Adjustment and Aggregate Output," Review of Economic Studies, vol. 49(4), pp. 517-531.

[34] Rotemberg, Julio J., and Michael Woodford (1997), “An Optimization-Based Econometric Framework for the Evaluation of Monetary Policy," in Bernanke, Ben S., and Julio. J. Rotemberg, eds., NBER Macroeconomics Annual 1997, vol. 12, Cambridge, MA: MIT Press, pp. 297-361.

[35] Rotemberg, Julio, and Michael Woodford (1999), "The Cyclical Behavior of Prices and Costs," in John Taylor and Michael Woodford, eds., Handbook of Macroeconomics, North-Holland: Elsevier, ed. 1, vol. 1(1), ch. 16, pp. 1051-1135.

[36] Rudd, Jeremy, and Karl Whelan (2005a), "Does Labor's Share Drive Inflation?" Journal of Money, Credit, and Banking, vol. 37(2), pp. 297-312.

[37] Rudd, Jeremy, and Karl Whelan (2005b), "New Tests of the New-Keynesian Phillips Curve," Journal of Monetary Economics, vol. 52(6), pp. 1167-1181.

[38] Rudd, Jeremy, and Karl Whelan (2006), "Can Rational Expectations Sticky-Price Models Explain Inflation Dynamics?" American Economic Review, vol. 96(1), pp. 303-320.

[39] Rudd, Jeremy, and Karl Whelan (2007), "Modeling Inflation Dynamics: A Critical Review of Recent Research," Journal of Money, Credit, and Banking, vol. 39(s1), pp. 155-170.

[40] Sbordone, Argia (2002), "Prices and Unit Labor Costs: A New Test of Price Stickiness," Journal of Monetary Economics, vol. 49(2), pp. 265-292.

[41] Sbordone, Argia (2005), "Do Expected Future Marginal Costs Drive Inflation Dynamics?" Journal of Monetary Economics, vol. 52(6), pp. 1183-1197.

[42] Scheufele, Rolf (2010), "Evaluating the German (New Keynesian) Phillips Curve," North American Journal of Economics and Finance, vol. 21, pp. 145-164.

[43] Smets, Frank, and Raffeal Wouters (2003), "An Estimated Dynamic Stochastic General Equilibrium Model of the Euro Area," Journal of the European Economics Association, vol. 1(5), pp. 1123-1175.

[44] Steinsson, Jon (2003), "Optimal Monetary Policy in an Economy with Inflation Persistence," Journal of Monetary Economics, vol. 50(7), pp. 1425-1456.

[45] Stock, James H., and Motohiro Yogo (2005), “Testing for Weak Instruments in Linear IV Regression," in Andrews, Donald W. K., and James H. Stock, eds., Identification and Inference for Econometric Models: Essays in Honor of Thomas Rothenberg, Cambridge: Cambridge University Press, pp. 80-108. 
[46] Stock, James H., Wright, Jonathan H., and Motohiro Yogo (2002), "A Survey of Weak Instruments and Weak Identification in Generalized Method of Moments," Journal of Business and Economic Statistics, vol. 20(4), pp. 518-529.

[47] Taylor, John B. (1979), "Staggered Wage Setting in a Macro Model," American Economic Review, vol. 69(2), pp. 108-113.

[48] Taylor, John B. (1980), "Aggregate Dynamics and Staggered Contracts," Journal of Political Economy, vol. 88(1), pp. 1-23.

[49] Thomas, Lloyd B. (1999), "Survey Measures of Expected U.S. Inflation," Journal of Economic Perspective, vol. 13, pp. 125-144.

[50] Verbeek, Marno (2012), A Guide to Modern Econometrics, 4th ed., New York: Wiley.

[51] Walsh, Carl E. (2010), Monetary Theory and Policy, 3rd ed., Cambridge: MIT Press.
[52] Woodford, Michael (1996), "Control of the Public Debt: A Requirement for Price Stability?” NBER Working Paper Series, no. 5684 .

[53] Woodford, Michael (2003), Interest and Prices, Princeton: Princeton University Press.

[54] Zhang, Chengsi, Osborn, Denise R., and Dong Heon Kim (2009), "Observed Inflation Forecasts and the New Keynesian Phillips Curve," Oxford Bulletin of Economics and Statistics, vol. 71, Issue 3, pp. 375-398.

[55] Zhang, Chengsi, and Joel Clovis (2010), "The New Keynesian Phillips Curve of Rational Expectations: A Serial Correlation Extension," Journal of Applied Economics, vol. 37(2), pp. 159-179 